\title{
Pig-to-human heart transplant slated to begin in 1996
}

The world's first xenotransplants of transgenic human-pig hearts into human recipients may be performed at the Papworth Hospital in Cambridgeshire, UK, early next year. This follows the announcement that Imutran Ltd, in Cambridge, has made significant headway in overcoming the problem of hyperacute rejection, a major hurdle in the use of animal organs for human transplantation.

At a meeting at the Royal Society of Medicine in London in September, David White, research director of Imutran, said that in the company's latest trials two out of ten monkeys were still alive more than 60 days after receiving pig hearts. The median survival was 40 days, whereas control (non-transgenic) pig hearts lasted 55 minutes. This contrasts with a maximum survival of 30 hours recorded using a similar approach by K.R. McCurry et al. in the United States (see Nature Medicine 1, 423-427; 1995).

The technique involves transferring genes for human complement inhibitor proteins into a pig fetus and inducing the pig to express the proteins, thereby tricking the human immune system into seeing the pig organ as human.

Each monkey received levels of immunosuppressants similar to those given human transplant recipients. Examination of two monkeys on days 34 and 35 with the pig hearts still beating showed them to be normal, with no signs of rejection.

Approvals for the trial will now be sought from the ethics committee at the hospital. It is expected that five or six people will receive pig hearts in the initial trial. Likely candidates will include people with rare tissue types for whom there is little chance of a suitable human donor.

John Wallwork, director of cardiac transplantation at Papworth, and a nonexecutive director of Imutran, said, "This research is now well advanced and we are making excellent progress in developing animal organs for transplantation - but it is important to understand that it will be several years before they are offered routinely as an alternative."

In the UK there are almost 6,000 people currently on the waiting list for a donor heart; in the USA 30,000 . Fewer than half are likely to receive a heart transplant.

NuAla MORAN London

\section{Transgenic regulations outlined}

In August, the US Food and Drug Administration (FDA) released its blueprint for the regulation of products derived from transgenic animals. Essentially, the 'points-to-consider' document outlines how the agency intends to regulate this new technology and and covers such aspects as the safety, purity and consistency of the final product. The document also spells out rules for companies developing transgenic animals as a source of

Milking transgenic goats for therapeutic proteins. therapeutic interest in their milk in large quantities. Yields of one gram of protein per litre of milk, an amount that would be difficult to obtain by conventional cell culture methods, have been obtained. Genzyme expects to test one of their products,

Antithrombin III, in clinical ext trials next April.

Transgenic animals repreษึँ sent a 'living and walking bioreactor' and, just as a company would be required to monitor what organs for human xenotransplantation.

Carol Ziomek of Genzyme Transgenics in Framingham, Massachusetts, characterizes the new document as a collection of relevant pre-existing points-to-consider documents. Genzyme is breeding transgenic goats that express proteins of goes into a bioreactor, the FDA will require companies to monitor the health of the transgenic animals and to ensure that their feed is free of pesticides or herbicides.

BARBARA NASTO New York

\section{DID YOU KNOW?}

Number of US medical school applicants reaches new high For the third year in succession, record numbers of people have applied to medical schools in the United States, according to figures released recently by the Association of American Medical Colleges (AAMC).

By late August, the number of hopefuls had reached 46,514 , up 1,149 from last year, when 45,365 applied but only one in three applicants was chosen. A full breakdown will be given at the association's meeting later this month in Washington, DC.

The reasons for the trend are unclear, but, as a rule, greater numbers of people apply to medical school when the job market for college graduates is poor, according to AAMC President Jordan J. Cohen. The number of college graduates in general, and science in particular, are also factors, he said.

DiANE GERSHON

Jobless totals in Germany - just what the doctor ordered

The number of doctors out of work in Germany is far lower than expected following reunification in 1990 . The latest government statistics show that as of September 1994, there were 7,810 unemployed doctors in Germany. Far gloomier forecasts had been projected at a meeting of the medical associations held in Berlin in 1989 (just months before the fall of the Berlin Wall). Frank-Ulrich Montgomery, president of the Clinical Doctors' Association, had predicted that as many as 53,000 doctors could be out of work by 1995 .

Even so, labour office officials say that some young doctors are still finding it difficult to find suitable positions: More than $\mathbf{7 0}$ percent of unemployed doctors are interns. Moreover, residencies in paediatrics and ophthalmology are still scarce. At the end of last year, there were 267,186 doctors in Germany (population 80 million), 40 percent in general practice, 48 percent in hospitals, and the rest in industry or the civil service.

KLAUS DALlibor Berlin

\section{Glaxo Wellcome trims the fat}

The fallout from the merger between Glaxo and Wellcome became apparent last month when the company announced 7,500 job losses as a result of the merger. The jobs will go by the end of 1998, saving the company $£ 700$ million (US $\$ 1.08$ billion) per annum.

NuAla MORAN London 